\title{
Research Paper: Electromyographic Activity of Se- lected Muscles During Squat Exercise With and Without Upper Limb Assistance
}

\author{
Amir Ali Jafarnezhadgero ${ }^{* *}$ (D), Ali Kavoosi² (D, Mehrdad Anbarian³ (D), Fatemeh Salari Esker ${ }^{4}$ Benjamin Senderling $^{5}$ \\ 1. Department of Sport Sciences, Faculty of Educational Science and Psychology, University of Mohaghegh Ardabili, Ardabil, Iran. \\ 2. Department of Sport Biomechanics, Faculty of Humanities, Broojerd Branch, Islamic Azad University, Broojerd, Iran. \\ 3. Department of Pathology and Sport Biomechanics, Faculty of Physical Education and Sport Sciences, Bu-Ali Sina University, Hamadan, Iran. \\ 4. Department of Sports Biomechanics, Faculty of Physical Education and Sports Sciences, University of Mazandaran, Babolsar, Iran. \\ 5. Center for Research in Human Movement Variability, University of Nebraska, Omaha, Nebraska, United States.
}

Funding: See Page 222

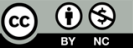

Article info:

Received: 17 Jul 2017

Accepted: 03 Dec 2017

Available Online: 01 Jan 2018
Citation Jafarnezhadgero AA, Kavoosi A, Anbarian M, Salari Esker F, Senderling B. Electromyographic Activity of Selected Muscles During Squat Exercise With and Without Upper Limb Assistance. Physical Treatments. 2018; 7(4):215-224. http:// dx.doi.org/10.32598/ptj.7.4.215

http://dx.doi.org/10.32598/ptj.7.4.215
Keywords:

Squat, Upper limb, Electromyography, Co-contraction

\begin{abstract}
A B S T R A C T
Purpose: A variation in squatting technique is using arms to actively push the bar up with the upper limbs which is common in bodybuilding. This study aimed to compare the Electromyography (EMG) activity of selected muscles during squat with and without upper limb assistance.
\end{abstract}

Methods: This was a quasi-experimental study. Fifteen healthy male power lifters (using the convenience sampling method) participated in this study. Participants performed 2 sets of 5 repetitions while squatting $70 \%$ of their one-repetition maximum with and without upper limb assistance. Surface EMG signals were collected from 6 muscles using a wireless electromyography with a sampling frequency of $1200 \mathrm{~Hz}$. The paired sample t test was used for statistical analyses at a significance level of $\mathrm{P}<0.05$. The obtained data were analyzed using SPSS.

Results: Average activity of the gluteus medius during the upward phase of squatting with upper limb assistance increased by $17.1 \%(\mathrm{P}=0.017)$, compared to squatting without upper limb assistance. Mean activity ratio of the vastus medialis during the downward phase with upper limb assistance showed a $6 \%$ decrease $(\mathrm{P}=0.008)$. During the downward phase of squatting with upper limb assistance, the mean activity ratio of the vastus medialis to vastus lateralis increased by $15 \%(\mathrm{P}=0.039)$. During the upward phase with upper limb assistance, the maximum activity of the gluteus medius increased by $22 \%(\mathrm{P}=0.043)$.

Conclusion: The activity level of the gluteus medius and the activity ratio of the vastus medialis to vastus lateralis increased as a result of squatting with upper limb assistance. This could possibly be helpful in the rehabilitation or prevention of injuries such as patellofemoral pain or iliotibial band friction syndrome. It could also have implications for training variation.

\footnotetext{
* Corresponding Author:

Amir Ali Jafarnezhadgero, $P h D$

Address: Department of Sport Sciences, Faculty of Educational Science and Psychology, University of Mohaghegh Ardabili, Ardabil, Iran. Phone: +98 (910) 5146214

E-mail: amiralijafarnezhad@gmail.com
} 


\section{Highlights}

- Average activity of the gluteus medius during the upward phase of squatting with upper limb assistance increased compared to squatting without upper limb assistance.

- Mean activity of the vastus medialis during the downward phase with upper limb assistance showed a decrease of 6 percent.

- During the downward phase of squatting with upper limb assistance, the mean activity ratio of the vastus medialis to vastus lateralis increased.

- During the upward phase with upper limb assistance, maximum activity of the gluteus medius increased.

\section{Plain Language Summary}

A variation in squatting technique, the use the arms to actively push the bar up with the upper limbs is common in bodybuilding. However this technique was not evaluated from scientific view. This study aimed to compare the Electromyographic (EMG) activity of selected muscles during squatting with and without upper limb assistance. Fifteen healthy male power lifters participated in this study. Participants performed two sets of five repetitions while squatting $70 \%$ of their one-repetition maximum with and without upper limb assistance. In six muscles surface EMG signals were collected using a wireless electromyography system. The activity level of the gluteus medius and the activity ratio of the vastus medialis to the vastus lateralis showed increases as a result of squatting with upper limb assistance. This could possibly be helpful in the rehabilitation and prevention of injuries such as patellofemoral pain or iliotibial band friction syndrome. It could also have implications for training variation.

\section{Introduction}

ower limb strengthening exercises are an important intervention in the treatment and prevention of lower limb injuries [1]. Knee and hip muscles strengthening exercises are considered as an important part in the rehabilitation protocols for hip, knee, and even ankle injuries [2]. Injuries could be caused by a number of factors, including the weakness of gluteus in controlling internal rotation movements, hip abduction, leading to patellofemoral pain [3], iliotibial band friction syndrome [4], and back pain [5, 6]. Although prospective studies are few in this field, crosssectional studies showed an abduction angle and a larger internal rotation in people with these injuries compared to healthy subjects [7-10].

Another possible cause of patellofemoral pain syndrome has been reported to be the lower activity ratio of the Vastus Medialis to the Vastus Lateralis (VM/VL) [11]. Moreover, the lower activity ratio of Hamstring to Quadriceps $(\mathrm{H} / \mathrm{Q})$ is associated with the anterior cruciate ligament injury [12-14]. Accordingly, it is necessary to introduce appropriate training methods to improve the function of these muscles and their activity ratios.
A large number of training programs for knee rehabilitation use squat as the basis for their exercises [1]. Evidently, squat exercise is an alternative to everyday functional activities such as climbing the stairs, sitting down, standing up, running, and hopping. Recent studies have recommended single leg squat in unstable conditions like Swiss ball use against a wall for further strengthening of the gluteal muscles $[1,4]$. The gluteal muscles activity increases with unstable squat, compared to stable squat, which is caused by the challenge posed to pelvic stability, resulting in increased hip adduction moment $[2,15,16]$.

Despite the increased activity of gluteal muscles, the increased hip adduction moment can raise injury risk during exercise, especially in the rehabilitation of patients with patellofemoral pain syndrome or iliotibial band friction syndrome [1]. For this reason, it seems necessary to explore an alternative exercise to typical squat for the rehabilitation of these patients that it improves the gluteal muscle activity and vastus medialis/ vastus lateralis activity ratios without increasing the hip adduction moment. Furthermore, if the new movement has a greater ratio of $\mathrm{H} / \mathrm{Q}$ activity, it may be useful for the prevention and rehabilitation of anterior cruciate ligament injury [17]. 
Another squat variation involves the use of the upper limbs to push the weight up during the upward phase of the movement. Performing this technique, the weight is pushed up changing muscle coordination. This difference in coordination could provide an alternative to squatting on an unstable surface by improving activity ratios and average muscle activity that increase injury risk. However, it is assumed that the aforementioned technique is usually performed as a personal preference rather than the result of a scientific study addressing the role of upper limb support during squat and its effect on lower body muscle activity. This study aimed to investigate the Electromyography (EMG) activity in lower limb muscles during squat with and without upper limb support.

\section{Materials and Methods}

This was a quasi-experimental study. Statistical population included subjects (age range: 20-40 years) who were sufficiently experienced (at least 3 years) in squatting with and without upper limb support and executed the 2 movements, regularly. Based on $\mathrm{G}^{*}$ power software calculation, a sample of at least 14 individuals was required in order to achieve a statistical power of 0.8 with an effect size of 0.8 at the significance level of 0.05 [18]. In total, 15 healthy male powerlifters (using the convenience sampling method) participated in this study with the Mean \pm SD age, weight, and height values of $27.2 \pm 7.6$ years, $79.9 \pm 7.9 \mathrm{~kg}$, and $179 \pm 10.6 \mathrm{~cm}$, respectively, in November 2016.

Written informed consent was obtained from all study participants and questionnaires related to sports medicine were completed by the participants prior to administering the tests. This study has been approved by the Ethics Committee of Mohaghegh Ardabili University according to the Declaration of Helsinki. None of the participants had a history of knee injuries, fractures in lower limb, or lower limbs and trunk disorders and surgeries. A week before conducting the test, the experiment was explained to the subjects and the one repetition maximum test was measured [19] for both techniques, in all subjects.

Feet were positioned shoulder width apart or slightly wider with toes pointed slightly outward during the squat [19] (Figure 1A). The legs position was kept the same for each set of repetitions. The start and the endpoint of the movements was $90^{\circ}$ flexion with full knee extension, and vice versa. The tempo of the movements was controlled by a metronome and the upward and downward phases took 1 second. Six Vicon cameras and 16 reflective markers were used to determine the beginning and end of each phase (Figure 1).

The markers were placed on the right and left lower limbs according to the Plug-in-Gait model. This study used a standard Olympic Bar Barbell (20.5 kg) and specific weights. Subjects embarked on a 10-minute stretching or other exercises to warm-up [20]. Proper execution of movements was supervised by an experienced coach. Surface EMG signals were collected using a wireless 16-channel electromyography unit (BTS FREEEMG 300 , BTS Bioengeering, Italy) with a sampling frequency of $1200 \mathrm{~Hz}$ and a signal-to-noise ratio of over 100 dB. Disposable $\mathrm{Ag} / \mathrm{AgCl}$ adhesive electrodes were used. Before placement of the electrode, hair was shaved in the

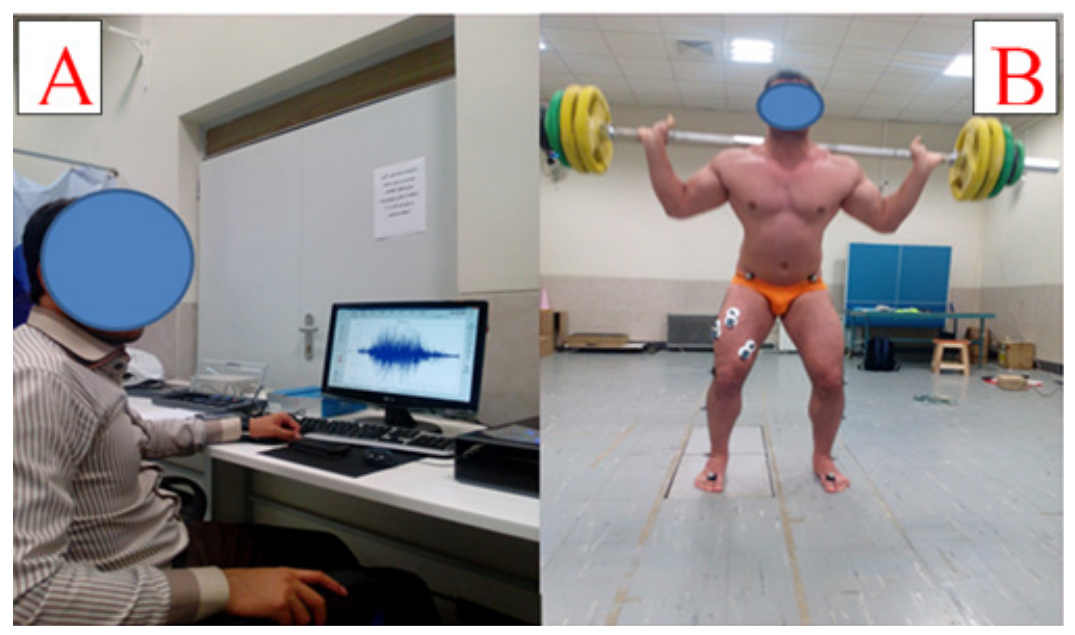

PHYSICAL TREA MENTS

Figure 1. (A) Observation of the accuracy of recorded muscle activity during isometric contraction in each muscle, (B) Positions of the subject, the electrodes, and markers from an anterior view 
site and the skin was cleaned with alcohol wipe to reduce the electrical resistance of the skin.

The electrodes were placed on the right hip muscles (Vastus Medialis [VM], Rectus Femoris [RF], Vastus Lateralis [VL], Semitendinosus [ST], Gluteus Medius [Glut. M], and Erector Spinae [ES], L3) according to the SENIAM European protocol [11]. The electrodes were placed in the interface between the nerve center of the muscle and distal tendon. Center to center spacing of the electrodes was $20 \mathrm{~mm}$. In order to ensure the accuracy of recorded activity of each muscle, the muscle signal was confirmed visually on a monitor when the subject isometrically contracted the muscle (Figure 1B). Subsequently, Maximum Voluntary Isometric Contraction (MVIC) of the muscles were collected and used to normalize the data.

The MVIC repetitions of the quadriceps group were recorded in a flexion state of $90^{\circ}$ for hip and knee joints during a knee extension movement in a sitting position. The MVIC repetitions of biceps femoris and semimembranosus muscles were recorded in the same position while flexing the knee joint [21]. The MVIC of the gluteus medius was recorded during isometric lying hip abduction [22]. In order to record MVIC of the erector spinae (L3), the subjects performed an isometric trunk extension in a prone position on a table while the lower limbs and trunk were fixed on the table by a belt [23].

For shortening the test time and avoiding fatigue, the subjects performed 2 MVIC repetitions of 4 seconds for each muscle or muscle group in random order. The subjects were given 2 min of rest between each repetition. After completion of the MVICs and a 5 min rest, the subjects performed each technique for 5 sets of 2 repetitions at $70 \%$ of their one repetition-max. A rest time of 5 min was allowed between each set. Implementation of two techniques was randomly directed among the total 10 sets. Squatting with upper limb assistance is shown in Figure 2. The upper limb assistance was not quantified during each repetition and was monitored by a trained coach. To prevent the effect of fatigue, a submaximal work load was used with a low number of repetitions and adequate rest between sets.

Data obtained from the surface electrodes were analyzed through EMG Analyzer software and band-pass filtered $(10$ to $500 \mathrm{~Hz})$. The myoelectric activity of muscles (root mean square error) was calculated during both upward and downward phases. Muscle activity was normalized by dividing the EMG activity by the muscle MVIC values multiplied by one hundred. The average and peak

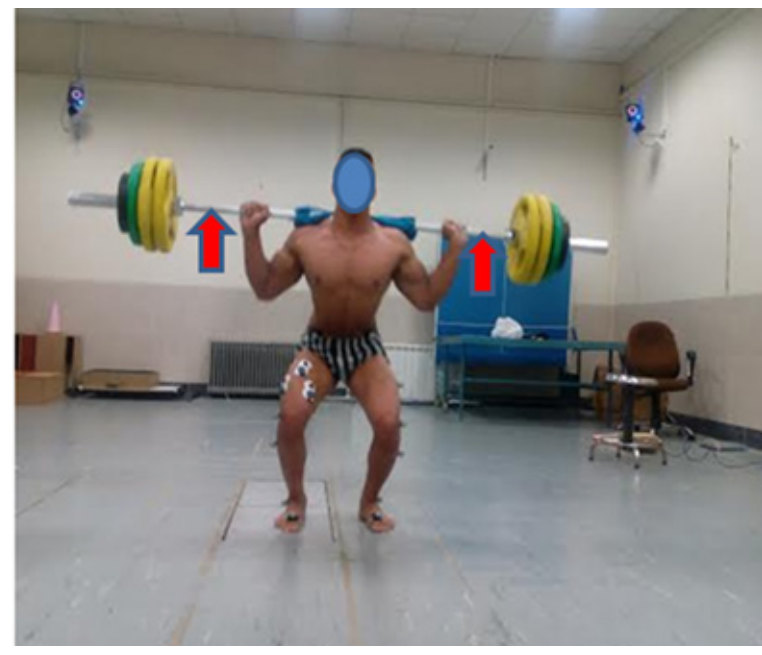

PHYSICAL TREA MENTS

Figure 2. Squatting with the support of upper limb

muscle activity during each phase was determined. The average ratio of the VM/VL activity and H/Q activity were also calculated and compared in both techniques.

The H/Q activities, respectively, were calculated by the sum of 2 biceps femoris and semitendinosus muscles and total activity of vastus medialis, rectus femoris, and vastus lateralis. The amount of general co-contraction was measured from the sum of electromyographic activities in all of the knee joint muscles [24]. Directed cocontraction between interior and exterior muscles as well as the flexor and extensor muscles of the knee joint were calculated by the following equation [24]:

Directed co-contraction = 1-(average agonist muscle activity/ average antagonist muscle activity)

When the directed co-contraction is closer to zero, cocontraction is higher, and if the number is closer to 1 or -1 , co-contraction will be lower.

The obtained data were statistically analyzed using SPSS. The Shapiro-Wilk test verified normal distribution of the obtained results. Accordingly, the paired $t$ test was used for statistical analyses at a significance level of $\mathrm{P}<0.05$.

\section{Results}

The Mean \pm SD values of one maximum repetition test during squatting with and without the upper limb assistance were $212 \pm 43 \mathrm{~kg}$ and $194 \pm 48 \mathrm{~kg}$, respectively. The results showed no significant differences $(\mathrm{P}>0.05)$ between the 2 squat techniques among the average activities of the vastus medialis, rectus femoris, vastus lateralis, semitendinosus, biceps femoris, and erector spinae 
Table 1. Average electromyography activity of muscles (\% MVIC) during squat with and without the help of upper limb

\begin{tabular}{|c|c|c|c|c|c|}
\hline Phase & Muscles & $\begin{array}{l}\text { Without Uupper Limb } \\
\text { Assistance }\end{array}$ & $\begin{array}{l}\text { With Upper Limb } \\
\text { Assistance }\end{array}$ & $\mathbf{t}$ & Sig. \\
\hline \multirow{7}{*}{ Upward } & VM & $107.4 \pm 60.2$ & $102.3 \pm 56.3$ & -0.620 & 0.545 \\
\hline & $\mathrm{RF}$ & $44.8 \pm 16.1$ & $47.1 \pm 25.9$ & 0.489 & 0.633 \\
\hline & VL & $114.2 \pm 58.7$ & $103.8 \pm 55.4$ & -1.630 & 0.125 \\
\hline & ST & $15.5 \pm 7.6$ & $14.9 \pm 8.0$ & -0.704 & 0.493 \\
\hline & $\mathrm{BF}$ & $13.6 \pm 5.9$ & $14.6 \pm 7.2$ & 0.986 & 0.341 \\
\hline & ES (L3) & $40.9 \pm 19.7$ & $44.7 \pm 23.7$ & 0.778 & 0.449 \\
\hline & Glut. M & $24.3 \pm 17.9$ & $28.5 \pm 21.2$ & 2.723 & $0.017 *$ \\
\hline \multirow{7}{*}{ Downward } & VM & $89.2 \pm 37.9$ & $94.5 \pm 46.6$ & 1.000 & 0.334 \\
\hline & $\mathrm{RF}$ & $51.3 \pm 18.2$ & $52.6 \pm 20.3$ & 0.287 & 0.778 \\
\hline & VL & $99.9 \pm 48.3$ & $88.3 \pm 45.5$ & -1.456 & 0.167 \\
\hline & ST & $9.3 \pm 4.2$ & $8.8 \pm 4.0$ & -3.0 .89 & $0.008^{*}$ \\
\hline & $\mathrm{BF}$ & $8.9 \pm 3.5$ & $11.9 \pm 14.4$ & 0.773 & 0.452 \\
\hline & ES (L3) & $23.9 \pm 28.8$ & $42.5 \pm 20.0$ & -0.759 & 0.461 \\
\hline & Glut. M & $25.1 \pm 21.7$ & $23.9 \pm 28.8$ & 0.316 & 0.757 \\
\hline
\end{tabular}

Abbreviations: VM: Vastus Medialis; RF: Rectus Femoris; VL: Vastus Lateralis; ST: Semitendinosus; BF: Biceps Femoris; Glut. M: Gluteus Medius; ES (L3): Erector Spinae

during the lifting phase (Table 1). However, average gluteus medius activity during the upward phase with upper limb assistance revealed approximately $17.1 \%$ increase $(\mathrm{P}=0.017)$, compared to the lack of the upper limb support. In addition, mean activity of the semitendinosus during the downward phase with upper limb assistance showed approximately $6 \%$ decrease $(\mathrm{P}=0.008)$ (Table 1$)$.

There were no significant differences between the average ratio of normalized electromyographic activity for

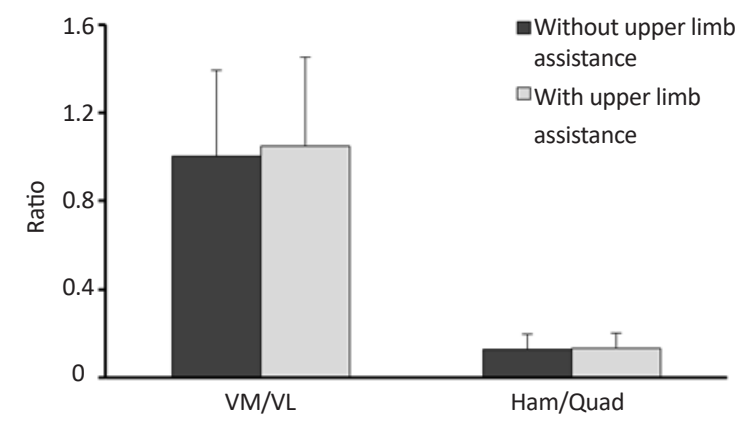

PHYSICAL TREA MENTS

Figure 3. Average VM/VL and $\mathrm{H} / \mathrm{a}$ ratios during the squat upward phase with and without upper limb support the VM/VL and H/Q during squatting with and without upper limb assistance $(\mathrm{P}>0.05)$ (Figure 3$)$. On the other hand, the VM/VL ratio of the downward phase with upper limb assistance increased by $15 \%$ compared to the same activity recorded without the support of upper limb $(\mathrm{P}=0.039)$. The $\mathrm{H} / \mathrm{Q}$ ratio of the squatting downward phase showed no significant differences between the 2 situations $(\mathrm{P}>0.05)$ (Figure 4).

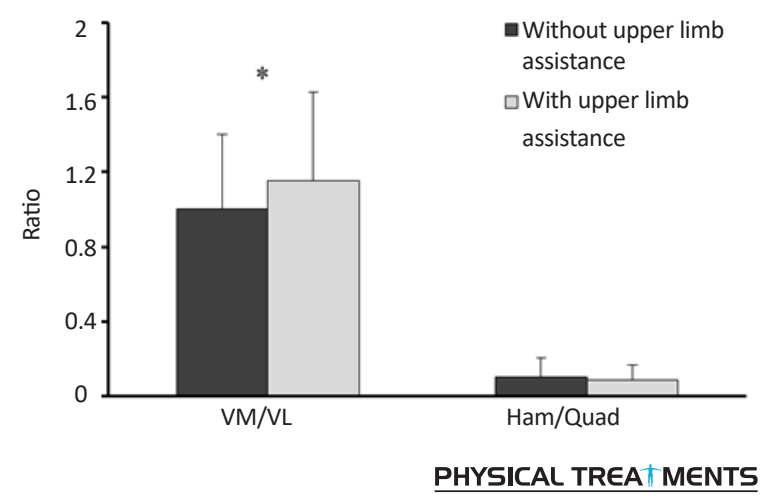

Figure 4. Average VM/VL and $\mathrm{H} / \mathrm{Q}$ ratios during the squat downward phase with and without upper limb support 


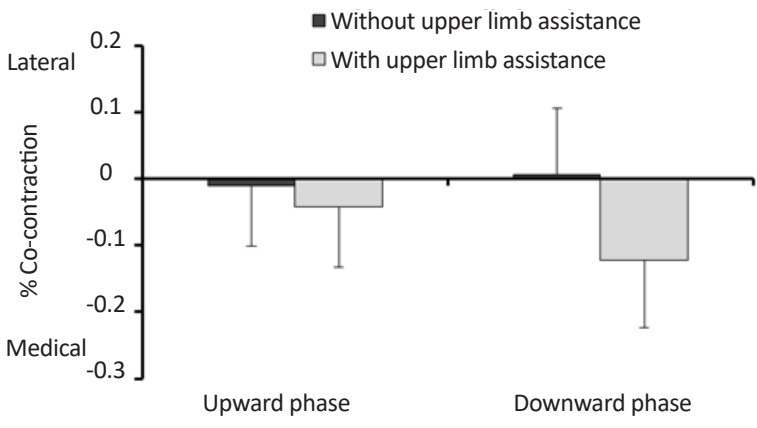

PHYSICAL TREA $\mid M E N T S$

Figure 5. Directed co-contraction of the mediolateral muscles of the knee joint in squat with and without support of upper limb

There were no significant differences between the mediolateral muscles of knee during upward and downward squat phases on the amounts of directed co-contraction with and without upper limb support (Figure 5). However, directed co-contraction of the mediolateral muscles of the knee during squatting without upper limb assistance was higher in the downward phase than the same in upper limb assistance, though the difference was not

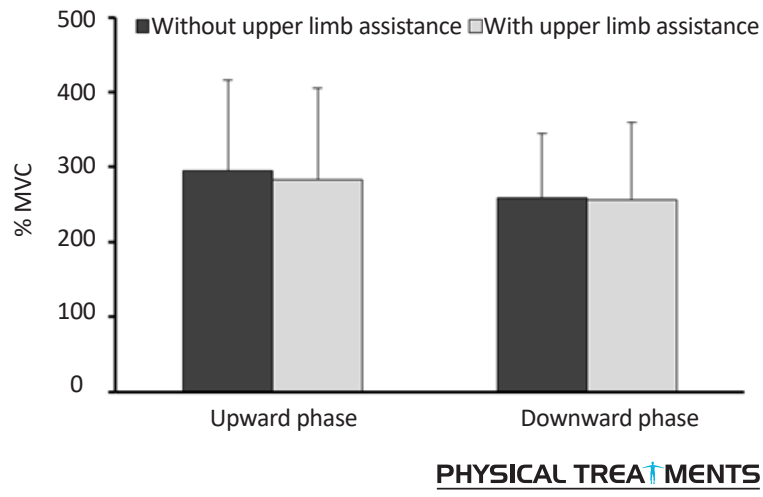

Figure 6. General co-contraction of the knee joint during the squat phase with and without the support of upper limb

statistically significant $(\mathrm{P}=0.087)$ (Figure 5). The general co-contraction around the knee joint showed no statistically significant differences $(\mathrm{P}>0.05)$ between two techniques (Figure 6).

Maximum muscle activities during the squat with and without use of upper extremity are demonstrated in Table 2. The results indicate that the maximum activity of

Table 2. Maximum level of electromyographic muscle activity (\% MVIC) during the squat phase with and without upper limb use

\begin{tabular}{|c|c|c|c|c|c|}
\hline Phase & Muscles & $\begin{array}{l}\text { Without Upper Limb } \\
\text { Assistance }\end{array}$ & $\begin{array}{l}\text { With Upper Limb } \\
\text { Assistance }\end{array}$ & $\mathbf{t}$ & Sig. \\
\hline & VM & $242.8 \pm 97.4$ & $242.9 \pm 113.5$ & 1.521 & 0.151 \\
\hline & RF & $115.7 \pm 49.4$ & $121.2 \pm 47.5$ & 0.936 & 0.365 \\
\hline & VL & $207.0 \pm 107.7$ & $201.2 \pm 113.8$ & -0.535 & 0.601 \\
\hline \multirow[t]{7}{*}{ Upward } & ST & $25.7 \pm 12.6$ & $26.4 \pm 14.6$ & 0.557 & 0.586 \\
\hline & $\mathrm{BF}$ & $24.4 \pm 11.5$ & $26.5 \pm 12.4$ & 1.345 & 0.200 \\
\hline & ES (L3) & $82.5 \pm 40.7$ & $86.8 \pm 36.6$ & 0.494 & 0.629 \\
\hline & Glut. M & $41.2 \pm 31.1$ & $48.7 \pm 35.5$ & 2.228 & $0.043^{*}$ \\
\hline & VM & $186.3 \pm 90.8$ & $199.5 \pm 113.9$ & 1.169 & 0.262 \\
\hline & $\mathrm{RF}$ & $119.7 \pm 55.9$ & $111.7 \pm 46.2$ & -1.265 & 0.227 \\
\hline & $\mathrm{VL}$ & $182.5 \pm 88.3$ & $177.3 \pm 100.6$ & -0.585 & 0.568 \\
\hline \multirow[t]{4}{*}{ Downward } & ST & $16.09 \pm 8.6$ & $16.7 \pm 8.5$ & 1.352 & 0.198 \\
\hline & $\mathrm{BF}$ & $16.5 \pm 9.0$ & $18.7 \pm 20.3$ & 0.390 & 0.702 \\
\hline & ES (L3) & $70.2 \pm 31.9$ & $76.1 \pm 36.2$ & 1.173 & 0.260 \\
\hline & Glut. M & $37.2 \pm 32.0$ & $38.9 \pm 37.6$ & 0.608 & 0.553 \\
\hline
\end{tabular}

$* \mathrm{P}<0.05$.

Abbreviations: VM: Vastus Medialis; RF: Rectus Femoris; VL: Vastus Lateralis; ST: Semitendinosus; BF: Biceps Femoris; Glut. M: Gluteus Medius; ES (L3): Erector Spinae 
the gluteus medius during the upward phase with assistance was $22 \%$ greater than the same without assistance $(\mathrm{P}=0.043)$. Maximum activities of other muscles in both upward and downward phases showed no significant differences $(\mathrm{P}>0.05)$ between two conditions (Table 2 ).

\section{Discussion}

The present study investigated the EMG activity of lower limb muscles during squat with and without upper limb support. The results indicate that the average activities of vastus medialis, rectus femoris, vastus lateralis, semi-chordal, biceps femoris, and erector spinae muscles during the upward phase were not significantly different between two squat styles of with and without upper extremity support. However, mean activity of the gluteus medius during the upward phase with upper limb assistance showed a significant increase, compared to the same condition without upper limb assistance. Weakness of the gluteus medius is a major cause of pelvic instability and back pain [6]. Its weakness is also related to increased hip adduction moment and knee valgus, which were involved in the susceptibility to patellofemoral pain [25-28], iliotibial band friction syndrome [4], and increased leg pronation [29]. Thus, due to the greater activity of this muscle during squat with upper limb assistance compared to typical squat, this technique could be used to prevent or rehabilitate people with the aforementioned injuries.

During the downward phase with upper limb assistance, the average activity of the semitendinosus muscle approximately declined by $6 \%$. The average ratio of the VM/VL ratio in the downward phase with upper limb assistance showed a significant increase compared to that with no assistance. Prior research suggest that two muscular mechanisms prevent outward displacement of the patella [30-33] which are impaired in those with patellofemoral pain.

The first one involves a difference in the activity of the vastus medialis compared to vastus lateralis [30]. The second one is associated with the higher activity of VM/ VL ratio in normal subjects compared to those with patellofemoral pain syndrome [31-33]. Given the higher VM/ VL ratio during squatting with upper limb support than that without the aid of upper limbs in the current study, it would be advantageous to repeat as much movements as possible during exercise in patients with patellofemoral pain syndrome as opposed to squatting without upper limb support. However, a better proof of this finding requires further studies, especially on such patients.
During the downward phase without upper limb assistance, the directed co-contraction of mediolateral muscles of the knee joint was higher than in squatting with upper limb assistance, although this difference was not statistically significant. Activation of the co-contraction of agonist and antagonist muscles of the mediolateral parts of the knee neutralizes the adduction moment exerted on the knee joint [24]. The increased co-contraction of the mediolateral muscles of the knee is associated with mediolateral osteoarthritis in the joint [34].

Knee osteoarthritis is considered as a leading cause of disability in old age [35-37]. Detection of the causes and prevention of knee osteoarthritis, especially in adolescence, could result in lower health care costs as well as a higher efficiency in performing daily activities. According to the present results of the two studied techniques, squatting without the help of the upper limb, particularly during the downward phase, can probably be recommended to strengthen the quadriceps in patients with medial compartment knee osteoarthritis. To further verify this issue, it is necessary to compare the mediolateral cocontraction of the knee joint during these two movements in patients with medial compartment knee osteoarthritis.

The H/Q ratio during both phases of the squat showed no significant differences between two conditions. A reduction in H/Q ratio accounts for risk of injury to the anterior cruciate ligament [38]. This study found no significant differences in $\mathrm{H} / \mathrm{Q}$ ratio during execution of the two different squat styles. There is no differences between 2 movements, with regard to strengthening the quadriceps muscles in people suffering from anterior cruciate ligament damage willing to put less strain on the ligament and simultaneously strengthen the muscle group.

The general knee joint co-contraction within the squat phases did not show any significant differences between the 2 techniques. Because an increase in general cocontraction often leads to increased joint loads [39-41], higher level of general co-contraction in the long term can increase loading on the joint tissues and cause tissue destruction and ultimately knee osteoarthritis. Our findings disclosed no differences in the rate of general co-contraction between two methods of squatting with and without upper extremity support.

Limitations of this research included lack of studying females. Pelvic geometry differs between males and females and could result in differences in muscle coordination during these two techniques, and the assistance provided by the upper limbs was also not quantified. In addition, this study disregarded potential mechanisms 
to reveal how these changes occur. A possible explanation could be that pushing the barbell up while leaning forward in squat increases activity of the posterior chain and consequently the gluteus medius.

Due to the higher levels of gluteus activity and a higher VM/VL ratio during squat with upper limb support, the movement could be recommended in the prevention and rehabilitation of patellofemoral pain syndrome, iliotibial band friction syndrome, and gluteal muscles weakness. Further studies on these populations are required to determine their impact on improving the rehabilitation.

\section{Ethical Considerations}

\section{Compliance with ethical guidelines}

This study has been approved by the Ethics Committee of Mohaghegh Ardabili University (Code number: 1395/12-145) according to the Declaration of Helsinki.

\section{Funding}

This research did not receive any specific grant from funding agencies in the public, commercial, or not-forprofit sectors.

\section{Conflict of interest}

The authors certify that they have no affiliation with or involvement in any organization or entity with any financial interest, or non-financial interest in the subject matter or materials discussed in this manuscript.

\section{Acknowledgements}

We thank all of the participants for their contributions.

\section{Reference}

[1] Barton CJ, Kennedy A, Twycross Lewis R, Woledge R, Malliaras $\mathrm{P}$, Morrissey D. Gluteal muscle activation during the isometric phase of squatting exercises with and without a Swiss ball. Physical Therapy in Sport. 2014; 15(1):39-46. [DOI:10.1016/j. ptsp.2013.02.006] [PMID]

[2] Powers CM. The influence of abnormal hip mechanics on knee injury: A biomechanical perspective. Journal of Orthopaedic \& Sports Physical Therapy. 2010; 40(2):42-51. [DOI:10.2519/ jospt.2010.3337] [PMID]

[3] Prins MR, Van Der Wurff P. Females with patellofemoral pain syndrome have weak hip muscles: A systematic review. Aus- tralian Journal of Physiotherapy. 2009; 55(1):9-15. [DOI:10.1016/ S0004-9514(09)70055-8]

[4] Fredericson M, Cookingham CL, Chaudhari AM, Dowdell BC, Oestreicher N, Sahrmann SA. Hip abductor weakness in distance runners with iliotibial band syndrome. Clinical Journal of Sport Medicine. 2000; 10(3):169-75. [DOI:10.1097/00042752200007000-00004] [PMID]

[5] Bussey MD, Kennedy JE, Kennedy G. Gluteus medius coactivation response in field hockey players with and without low back pain. Physical Therapy in Sport. 2016; 17:24-9. [DOI:10.1016/j. ptsp.2015.03.002] [PMID]

[6] Marshall PW, Patel H, Callaghan JP. Gluteus medius strength, endurance, and co-activation in the development of low back pain during prolonged standing. Human Movement Science. 2011; 30(1):63-73. [DOI:10.1016/j.humov.2010.08.017] [PMID]

[7] Noehren B, Davis I, Hamill J. ASB Clinical Biomechanics Award Winner 2006: Prospective study of the biomechanical factors associated with iliotibial band syndrome. Clinical Biomechanics. 2007; 22(9):951-6. [DOI:10.1016/j.clinbioe mech.2007.07.001] [PMID]

[8] Dierks TA, Manal KT, Hamill J, Davis IS. Proximal and distal influences on hip and knee kinematics in runners with patellofemoral pain during a prolonged run. Journal of Orthopaedic \& Sports Physical Therapy. 2008; 38(8):448-56. [DOI:10.2519/jospt.2008.2490] [PMID]

[9] Willson JD, Davis IS. Lower extremity mechanics of females with and without patellofemoral pain across activities with progressively greater task demands. Clinical Biomechanics. 2008; 23(2):203-11. [DOI:10.1016/j.clinbiomech.2007.08.025] [PMID]

[10] Souza RB, Powers CM. Differences in hip kinematics, muscle strength, and muscle activation between subjects with and without patellofemoral pain. Journal of Orthopaedic \& Sports Physical Therapy. 2009; 39(1):12-9. [DOI:10.2519/ jospt.2009.2885] [PMID]

[11] Smith T, Chester R, Cross J, Hunt N, Clark A, Donell S. Rehabilitation following first-time patellar dislocation: A randomised controlled trial of purported vastus medialis obliquus muscle versus general quadriceps strengthening exercises. The Knee. 2015; 22(4):313-20. [DOI:10.1016/j.knee.2015.03.013] [PMID]

[12] Husted RS, Bencke J, Andersen LL, Myklebust G, Kallemose $\mathrm{T}$, Lauridsen $\mathrm{HB}$, et al. A comparison of hamstring muscle activity during different screening tests for non-contact ACL injury. The Knee. 2016; 23(3):362-6. [DOI:10.1016/j. knee.2016.02.004] [PMID]

[13] Pellicer-Chenoll M, Serra Aó P, Cabeza-Ruiz R, Pardo A Aranda R, González L. Comparison of conventional hamstring/quadriceps ratio between genders in level-matched soccer players. Revista Andaluza de Medicina del Deporte. 2017; 10(1):14-8. [PMID] [PMCID]

[14] Bryant A, Newton R, Bronks R, Randle R. Activation of the quadriceps and hamstrings during isokinetic knee extension with ACL deficiency and following reconstruction using either the patella or hamstring tendon grafts. Journal of Science and Medicine in Sport. 2002; 5(4):65-7. [DOI:10.1016/S14402440(02)80165-7]

[15] Distefano LJ, Blackburn JT, Marshall SW, Padua DA. Gluteal muscle activation during common therapeutic exercises. Journal of Orthopaedic \& Sports Physical Therapy. 2009; 39(7):53240. [DOI:10.2519/jospt.2009.2796] [PMID] 
[16] Hewett TE, Myer GD, Ford KR. Anterior cruciate ligament injuries in female athletes part 1 , mechanisms and risk factors. The American Journal of Sports Medicine. 2006; 34(2):299-311. [DOI:10.1177/0363546505284183] [PMID]

[17] Biscarini A, Contemori S, Busti D, Botti FM, Pettorossi VE. Knee flexion with quadriceps cocontraction: A new therapeutic exercise for the early stage of ACL rehabilitation. Journal of Biomechanics. 2016; 49(16):3855-60. [DOI:10.1016/j.jbioi mech.2016.10.026] [PMID]

[18] Faul F, Erdfelder E, Lang AG, Buchner A. G*Power 3: A flexible statistical power analysis program for the social, behavioral, and biomedical sciences. Behavior Research Methods. 2007; 39(2):175-91. [DOI:10.3758/BF03193146] [PMID]

[19] Cotterman ML, Darby LA, Skelly WA. Comparison of muscle force production using the Smith machine and free weights for bench press and squat exercises. The Journal of Strength \& Conditioning Research. 2005; 19(1):169-76. [DOI:10.1519/14433.1]

[20] Walker S, Peltonen H, Avela J, Häkkinen K. Kinetic and electromyographic analysis of single repetition constant and variable resistance leg press actions. Journal of Electromyography and Kinesiology. 2011; 21(2):262-9. [DOI:10.1016/j. jelekin.2010.12.004] [PMID]

[21] Hermens HJ, Freriks B, Merletti R, Stegeman D, Blok J, Rau G, et al. European recommendations for surface electromyography. Roessingh Research and Development. 1999; 8(2):13-54.

[22] Semciw AI, Neate R, Pizzari T. A comparison of surface and fine wire EMG recordings of gluteus medius during selected maximum isometric voluntary contractions of the hip. Journal of Electromyography and Kinesiology. 2014; 24(6):835-40. [DOI:10.1016/j.jelekin.2014.08.015] [PMID]

[23] Vera Garcia FJ, Moreside JM, McGill SM. MVC techniques to normalize trunk muscle EMG in healthy women. Journal of Electromyography and Kinesiology. 2010; 20(1):10-6. [DOI:10.1016/j.jelekin.2009.03.010] [PMID]

[24] Heiden TL, Lloyd DG, Ackland TR. Knee joint kinematics, kinetics and muscle co-contraction in knee osteoarthritis patient gait. Clinical Biomechanics. 2009; 24(10):833-41. [DOI:10.1016/j. clinbiomech.2009.08.005] [PMID]

[25] Cowan S. The role of gluteus medius in patellofemoral pain. Journal of Science and Medicine in Sport. 2006; 9:6. [DOI:10.1016/j.jsams.2006.12.010]

[26] Ott B, Cosby NL, Grindstaff TL, Hart JM. Hip and knee muscle function following aerobic exercise in individuals with patellofemoral pain syndrome. Journal of Electromyography and Kinesiology. 2011; 21(4):631-7. [DOI:10.1016/j. jelekin.2011.04.006] [PMID]

[27] Esculier JF, Roy JS, Bouyer LJ. Lower limb control and strength in runners with and without patellofemoral pain syndrome. Gait \& Posture. 2015; 41(3):813-9. [DOI:10.1016/j. gaitpost.2015.02.020] [PMID]

[28] Willson JD, Kernozek TW, Arndt RL, Reznichek DA, Straker JS. Gluteal muscle activation during running in females with and without patellofemoral pain syndrome. Clinical Biomechanics. 2011; 26(7):735-40. [DOI:10.1016/j.clinbioi mech.2011.02.012] [PMID]

[29] Chuter VH, de Jonge XAJ. Proximal and distal contributions to lower extremity injury: A review of the literature. Gait \&
Posture. 2012; 36(1):7-15. [DOI:10.1016/j.gaitpost.2012.02.001] [PMID]

[30] Briani RV, de Oliveira Silva D, Pazzinatto MF, Ferreira AS, Ferrari D, de Azevedo FM. Delayed onset of electromyographic activity of the vastus medialis relative to the vastus lateralis may be related to physical activity levels in females with patellofemoral pain. Journal of Electromyography and Kinesiology. 2016; 26:137-42. [DOI:10.1016/j.jelekin.2015.10.012] [PMID]

[31] Makhsous M, Lin F, Koh JL, Nuber G, Zhang LQ. In vivo and noninvasive load sharing among the vasti in patellar malalignment. Medicine and Science in Sports and Exercise. 2004; 36(10):1768-75. [DOI:10.1249/01.MSS.0000142302.54730.7F] [PMID]

[32] Sawatsky A, Bourne D, Horisberger M, Jinha A, Herzog W. Changes in patellofemoral joint contact pressures caused by vastus medialis muscle weakness. Clinical Biomechanics. 2012 27(6):595-601. [DOI:10.1016/j.clinbiomech.2011.12.011] [PMID]

[33] Sheehan FT, Borotikar BS, Behnam AJ, Alter KE. Alterations in in vivo knee joint kinematics following a femoral nerve branch block of the vastus medialis: Implications for patellofemoral pain syndrome. Clinical Biomechanics. 2012; 27(6):525-31. [DOI:10.1016/j.clinbiomech.2011.12.012] [PMID] [PMCID]

[34] Hodges PW, van den Hoorn W, Wrigley TV, Hinman RS, Bowles KA, Cicuttini F, et al. Increased duration of co-contraction of medial knee muscles is associated with greater progression of knee osteoarthritis. Manual Therapy. 2016; 21:151-8. [DOI:10.1016/j.math.2015.07.004] [PMID]

[35] Rudolph KS, Schmitt LC, Lewek MD. Age-related changes in strength, joint laxity, and walking patterns: Are they related to knee osteoarthritis. Physical Therapy. 2007; 87(11):1422-32. [DOI:10.2522/ptj.20060137] [PMID] [PMCID]

[36] Ettinger WH, Afable RF. Physical disability from knee osteoarthritis: The role of exercise as an intervention. Medicine \& Science in Sports \& Exercise. 1994; 26(12):1435-40. [DOI:10.1249/00005768-199412000-00004] [PMID]

[37] Lawrence RC, Helmick CG, Arnett FC, Deyo RA, Felson DT, Giannini EH, et al. Estimates of the prevalence of arthritis and selected musculoskeletal disorders in the United States. Arthritis \& Rheumatism. 1998; 41(5):778-99. [DOI:10.1002/15290131(199805)41:53.0.CO;2-V]

[38] Letafatkar A, Rajabi R, Tekamejani EE, Minoonejad H. Effects of perturbation training on knee flexion angle and quadriceps to hamstring cocontraction of female athletes with quadriceps dominance deficit: Pre-post intervention study. The Knee. 2015 22(3):230-6. [DOI:10.1016/j.knee.2015.02.001] [PMID]

[39] Lloyd DG, Buchanan TS. Strategies of muscular support of varus and valgus isometric loads at the human knee. Journal of Biomechanics. 2001; 34(10):1257-67. [DOI:10.1016/S00219290(01)00095-1]

[40] Andriacchi T, Andersson G, Örtengren R, Mikosz R. A study of factors influencing muscle activity about the knee joint. Journal of Orthopaedic Research. 1983; 1(3):266-75. [DOI:10.1002/jor.1100010306] [PMID]

[41] Zhang LQ, Xu D, Wang G, Hendrix RW. Muscle strength in knee varus and valgus. Medicine and Science in Sports and Exercise. 2001; 33(7):1194-9. [DOI:10.1097/00005768200107000-00018] [PMID] 
